\title{
SEPARATION AND CHARACTERISATION OF MINERAL OIL SLICKS AND NEWLY FORMED SEA ICE IN L-BAND SYNTHETIC APERTURE RADAR
}

\author{
A. Malin Johansson, Martine M. Espeseth, Camilla Brekke and Stine Skrunes \\ UiT The Arctic University of Norway, Department of Physics and Technology
}

\begin{abstract}
Maritime activities in the Arctic Ocean is increasing and consequently the risk for an oil spill there is rising. Synthetic Aperture Radar (SAR) is used operationally to detect and monitor oil slicks and for sea ice monitoring and observations. Leads are often used for ship routing and within the leads newly formed sea ice is often present. Separation between the low backscatter areas that constitutes oil slicks and newly formed sea ice is therefore important. Here we compare fully polarimetric L-band SAR images overlapping both oil slicks and newly formed sea ice. For the oil slicks airborne Uninhabited Aerial Vehicle SAR (UAVSAR) images are used and for the newly formed sea ice an ALOS-2 PALSAR-2 image is used. Using a set of multi-polarization features we observe that the coefficient of variation of the polarization difference can be used to separate the two.
\end{abstract}

Index Terms - Synthetic Aperture Radar, ALOS-2, UAVSAR, mineral oil, sea ice, polarimetry

\section{INTRODUCTION}

The Arctic is experiencing a reduced and thinning sea ice cover [1], and this change is expected to lead to an increase in maritime activities. For ship route planning newly formed sea ice areas, such as leads, are favoured. Should an oil spill occur in the sea ice infested waters it is important to be able to separate the oil spill from newly formed sea ice. Here we perform a comparison using fully polarimetric L-band Synthetic Aperture Radar (SAR) data overlapping controlled oil spill releases (airborne Uninhabited Aerial Vehicle SAR (UAVSAR)) and newly formed sea ice (ALOS-2 PALSAR2). L-band SAR is chosen due to the good signal to noise ratio (SNR) as the low backscatter values of the oil spills and the newly formed sea ice are dominated by the additive noise component. For comparison the incidence angle is kept consistent between the two datasets.

This research is financed by CIRFA (RCN Grant no. 237906) and Petromaks-2 (RCN Grant no. 280616).

\section{BACKGROUND THEORY}

Polarimetric SAR can be used to detect marine oil spills (see e.g., [2] and references therein) and have been shown to improve sea ice classification (see e.g. [3, 4]) and oil spill characterization [2]. The radar signal consists of both signal and background noise, where the noise-equivalentsigma-zero (NESZ) is defined as when the radar backscatter coefficient of an area is equal in strength to the sensor noise. In [5] they found that a SNR of at least $10 \mathrm{~dB}$ is needed in order to ensure that the scattering properties are not too affected by noise. Both oil slicks and the newly formed sea ice are low backscatter phenomena and due to the better signal to noise ratio (SNR) only the co-polarization channels or features derived from them are included in this study. The selection of parameters, shown in Table 1, are based on previous successful separation of mineral oil slicks from the surrounding open water ([2] and references therein), and separation of newly formed sea ice from surrounding open water and sea ice $[4,6]$. To address relative changes in the surface texture the coefficient of variation (CV) for PD and $\gamma_{H H / V V}$ is included.

Table 1: Overview of polarimetric features. The first letter in the subscript refers to the transmitted polarization and the second the received polarization. The backscattering coefficients are given in $\mathrm{dB}$ and the $\langle\cdot\rangle$ indicates averaging over a neighbourhood of $\mathrm{N}$ pixels. $f$ refers to $\mathrm{PD}$ or $\gamma_{H H / V V}$.

\begin{tabular}{c|c} 
Feature & Definition \\
\hline Backscatter coefficient & $\sigma_{H H}^{0}=\left\langle\left|S_{H H}\right|^{2}\right\rangle$ \\
Backscatter coefficient & $\sigma_{V V}^{0}=\left\langle\left|S_{V V}\right|^{2}\right\rangle$ \\
Polarization difference & $P D=\sigma_{H H}^{0}-\sigma_{V V}^{0}$ \\
Co-polarization ratio & $\gamma_{H H / V V}=\sigma_{H H}^{0} / \sigma_{V V}^{0}$ \\
Coefficient of variation & $C V=\operatorname{std}(f) /$ mean $(f)$ \\
\hline
\end{tabular}

PD has been shown by e.g., $[2,7]$ to have a low sensitivity to the incidence angle for oil slicks and this was also found to be the case for newly formed sea ice [6]. The definition of PD [7] means that the feature becomes independent of noise, given that the noise in the $\mathrm{HH}$ and VV channels are the same, 
(a)

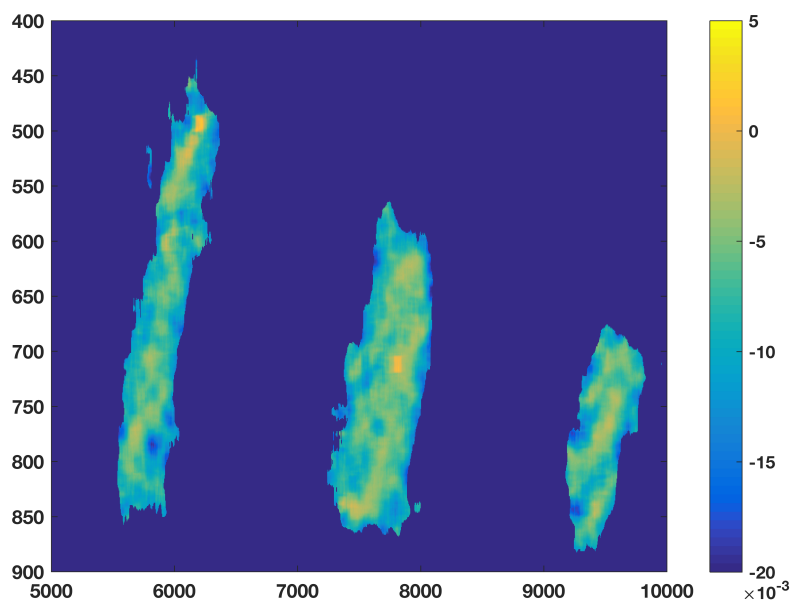

(b)

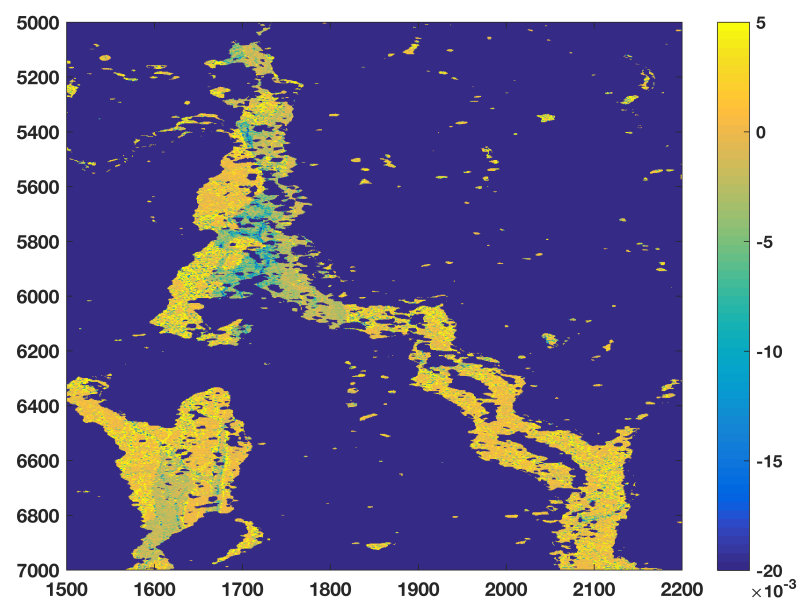

Fig. 1: PD values for (a) UAVSAR oil spill, where the leftmost spill is E40, the middle is E60 and the rightmost is E80. (b) ALOS-2 newly formed sea ice. On both images a segmentation mask has been applied and therefore all surrounding areas are shown in dark blue.

though noise may affect the standard deviation of the PD. In addition, PD has a good contrast to the surrounding open water and thicker sea ice for both the oil slicks and the newly formed sea ice $[7,6]$ and can therefore also be used to detect oil slicks and newly formed sea ice.

Table 2: Specifics of fully polarimetric data used in this study. The * indicates nominal values. The incidence angles given are the center incidence angles covering the dark features.

\begin{tabular}{c|c|c} 
Mission & UAVSAR & ALOS-2 \\
\hline Frequency band & L $(1.2 \mathrm{GHz})$ & L $(1.2 \mathrm{GHz})$ \\
Acquisition mode & PolSAR & Stripmap \\
Polarization mode & Full $($ Quad $)$ & Full $($ Quad $)$ \\
Rg resolution* & $2.5 \mathrm{~m}$ & $5.1 \mathrm{~m}$ \\
Az resolution * & $0.8 \mathrm{~m}$ & $4.3 \mathrm{~m}$ \\
Width & $22 \mathrm{~km}$ & $40-50 \mathrm{~km}$ \\
Length (per frame) & $22 \mathrm{~km}$ & $70 \mathrm{~km}$ \\
Incidence angle & $37^{\circ}$ & $36.55^{\circ}$ \\
Noise Equivalent Sigma & $-50 \mathrm{~dB}$ & $-36.0 \mathrm{~dB}(\mathrm{HH})$ \\
Zero (NESZ) & & $-46.0 \mathrm{~dB}(\mathrm{HV})$ \\
\hline
\end{tabular}

$\gamma_{H H / V V}$ has been proven useful in sea ice classifications with particular emphasis on the thinner sea ice types (see e.g., $[8,6]$ and references therein). $\gamma_{H H / V V}$ is independent of the capillary-gravity wave dampening but dependent on the incidence angle, the dielectric constant and the large-scale surface roughness tilt angles [9]. The $\gamma_{H H / V V}$ are lower for open water compared to oil slicks and higher for thicker sea ice compared to newly formed sea ice. The $\gamma_{H H / V V}$ values are dependent on the sea ice thickness where the values in- crease with increasing sea ice thickness [10]. Furthermore, the values for both the oil slicks and the newly formed sea ice decrease with increasing incidence angle [9, 10].

\section{DATA}

The oil slick data is taken from the annual Oil-On-Water exercises at the abandoned Frigg field in the North Sea (around $\left.60^{\circ} \mathrm{N}, 2.5^{\circ} \mathrm{E}\right)$ on $10 \mathrm{June} 2015[2,11]$. The airborne UAVSAR was flown on a Gulfstream-III aircraft and three different mineral oil emulsions were released into the open water. The emulsions have different volumetric oil fractions, $40 \%$ (E40), $60 \%$ (E60) and 80\% (E80), and are all based on Troll and Oseberg crude oils. Weather observations from the ships participating in the exercise show wind speeds of 9-11 m/s. Further information about the sensor can be found in Table 2 and in [12]. The incidence angle for the oil slicks are between $35^{\circ}$ and $38^{\circ}$. For the analysis here two different UAVSAR images are used (Oil \#1 and Oil \#2), acquired at different times implying that age of the oil slicks vary. The oil slicks were extracted using a mask removing the open water surrounding the oil slicks. The mask was generated using the algorithm presented in [13] where the algorithm separates the image into different regions based on the statistical properties of the data. The mask is the same as the one used in [2].

The ALOS-2 L-band SAR images were acquired to overlap with the N-ICE2015 sea ice drift campaign in spring of 2015 [14]. The study area was in the Arctic Ocean north of Svalbard, between $80^{\circ} \mathrm{N}$ to $84^{\circ} \mathrm{N}$ and $8^{\circ} \mathrm{W}$ to $25^{\circ} \mathrm{E}$. The sea ice within the study area was primarily a mixture of first and second year ice though areas of thinner sea ice types such as nilas, young grey ice and young white ice were observed. The 
(a)

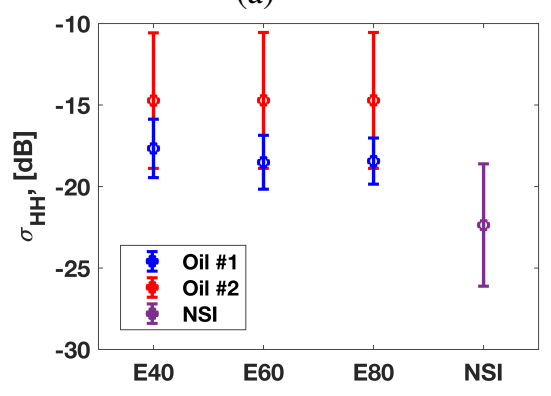

(d)

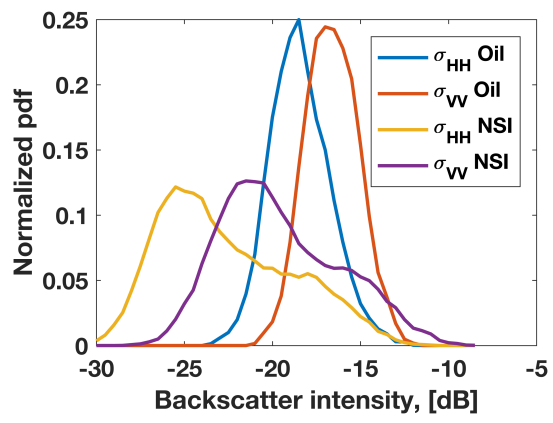

(b)

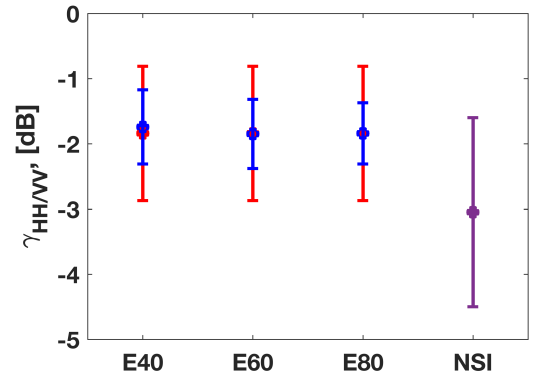

(e)

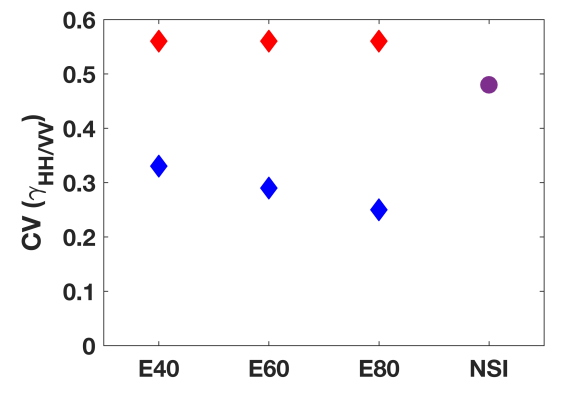

(c)

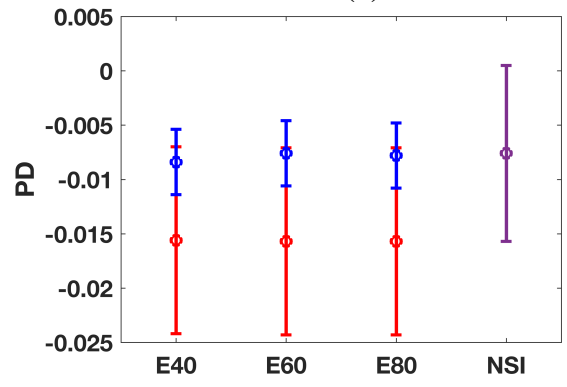

(f)

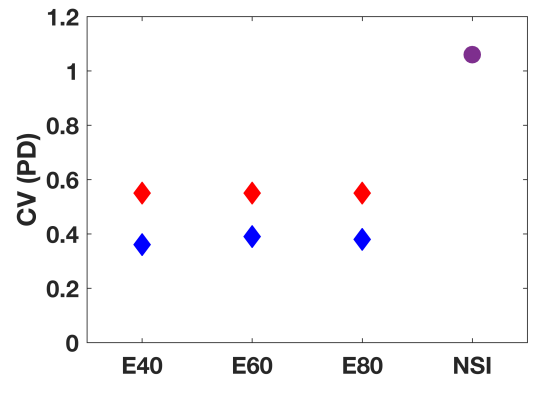

Fig. 2: Multi-polarization feature mean \pm standard deviation results for the oil slicks and the newly formed sea ice (NSI) in (a) $\sigma_{H H}$ (b) $\gamma_{H H / V V}$ and (c) PD. For the oil slicks two UAVSAR images are used and therefore two results are presented for each of the three different oil slick blends. The results from the first image (Oil \#1) is shown in blue and the second (Oil \#2) in red. For the NSI (purple) only one value is presented. (d) Normalised probability density function (pdf) for the $\sigma_{x x}$ values for the VV and HH channel for all three oil slicks in Oil \#1) and the NSI, (e) CV values for $\gamma_{H H / V V}$ and (f) CV values for PD.

satellite dataset was acquired with high temporal and spatial correlation with JAXA's L-band (ALOS-2) PALSAR-2 sensor and the acquisition mode is High-sensitive Quad polarimetry (HBQ) (Table 2) and overlap with in-situ data such as; sea ice thickness, sea ice type, wind and temperature. These observations indicate that the newly formed sea ice is $<30 \mathrm{~cm}$ thick. The incidence angle for the newly formed sea ice was on average $36.55^{\circ}$. The newly formed sea ice areas were extracted using an Artificial Neural Network [8] sea ice classification.

The airborne and satellite images were calibrated and an averaging filter was applied to the scenes to reduce speckle. The difference in pixel sizes meant that a different sized filter was applied to the different images and thereby obtain a comparable resolution across the scenes. For the UAVSAR images it was set to $15 \times 61$ and for the ALOS-2 scene it was $5 \times 5$.

\section{RESULTS AND DISCUSSION}

In Figure 1 the PD values for a subset of one of the oil slick images (Oil \#1)and a subset of the sea ice image is shown. PD is not currently used as a standard parameter to detect and characterise sea ice.

The results for the different multi-polarization features and type of dark slick are presented in Figure 2. We ob- serve that the L-band SAR images over the oil slick and newly formed sea ice satisfies the $10 \mathrm{~dB}$ SNR level defined in [5] and as such contain a valid signal and the results can therefore be related to differences between the two types of low backscatter areas. The two dark phenomena have comparable backscatter values, though the newly formed sea ice values are lower than the oil slicks values. The relatively high values for the oil slicks are likely a result of the high wind speeds observed during the exercise $[2,11]$. The standard deviation for the oil slicks backscatter values are smaller than for the newly formed sea ice areas and in addition is the separation between the mean values in the $\sigma_{H H}^{0}$ and $\sigma_{V V}^{0}$ smaller (Figure 2d). The large variation in backscatter values for newly formed sea ice was already noted upon in e.g. [15] and is likely a consequence of small scale surface structures, such as fingering and rafting, as well as thickness changes, whereas the oil slicks are comparatively more homogenous. The oil slick spatial extents are increasing with time [11] and this may be the reason for the larger backscatter variation in the second oil slick image (Figure 2a).

The larger separation between the $\sigma_{H H}^{0}$ and $\sigma_{V V}^{0}$ in the newly formed sea ice is reflected in the higher absolute $\gamma_{H H / V V}$ value in Figure 2 b. The $\gamma_{H H / V V}$ has different values for the oil slick and the newly formed sea ice though the standard deviation for the newly formed sea ice implies 
that they may overlap. The $\mathrm{CV}$ of $\gamma_{H H / V V}$ is also similar between the oil slick and the newly formed sea ice. These observations combined with the dependency of $\gamma_{H H / V V}$ on the incidence angle, sea ice thickness as well as the sensitivity to SNR might make establishing a standard based on $\gamma_{H H / V V}$ for separation of oil slick and newly formed sea ice difficult.

Within the two oil slick images the PD values for the three different oil slicks, E40, E60 and E80 are consistent, though variations between the two scenes are observed in Figure 2c. The second UAVSAR image (red) taken later during the day when the oil slicks were older has higher backscatter values and correspondingly higher PD values. From this we observe that even though the $\sigma_{H H}^{0}$ and PD can be used to separate the oil slicks and the newly formed sea ice from the surroundings they are not consistently suitable for separation from each other. However, coefficient of variation for PD have distinctly different values. The textural information separating the oil slicks and the newly formed sea ice may therefore be promising. Further investigations will be conducted using both Land C-band SAR, where care will be taken to ensure sufficient SNR levels.

\section{ACKNOWLEDGEMENT}

The authors would like to thank NOFO for including our experiment in their exercise and for providing ground truth data, and scientists at the Norwegian Meteorological Institute for collecting metocean data. UAVSAR data are courtesy of NASA-JPL. The ALOS-2 PALSAR-2 scene was provided by JAXA under the 4th Research Announcement program (PI: Torbjørn Eltoft, ALOS PI No.1199).

\section{REFERENCES}

[1] J. Stroeve, T. Markus, W. Meier, and J. Miller, "The Arctic's rapidly shrinking sea ice cover: A research synthesis," Climate Change, vol. 110, pp. 1005-1027, 2012.

[2] S. Skrunes, C. Brekke, C. Jones, M. Espeseth, and B. Holt, "Effect of wind direction and incidence angle on polarimetric SAR observations of slicked and unslicked sea surfaces," Remote Sens. Env., vol. 213, pp. 73-91, 2018.

[3] M. Dabboor and T. Geldsetzer, "Towards sea ice classification using simulated RADARSAT Constellation Mission compact polarimetric SAR imagery," Remote Sens. Env., vol. 140, pp. 189-195, 2014.

[4] T. Geldsetzer, M. Arkett, T. Zagon, F. Charbonneau, J. J. Yackel, and R. K. Scharien, "All-Season CompactPolarimetry C-band SAR Observations of Sea Ice," Canadian J. Remote Sens., vol. 41, no. 5, pp. 485-504, 2015.
[5] M. M. Espeseth, S. Skrunes, C. Brekke, and A. M. Johansson, "The impact of noise on polarimetric Radarsat2 data covering oil slicks," IEEE Int. Geosci. Remote Sens. Symp., 2019.

[6] A. M. Johansson, C. Brekke, G. Spreen, and J. A. King, "X-, C-, and L-band SAR signatures of newly formed sea ice in Arctic leads during winter and spring," Remote Sens. Env., vol. 204, no. Supplement C, pp. 162 - 180, 2018.

[7] V. Kudryavtsev, B. Chapron, A. Myasoedov, F. Collard, and J. Johannessen, "On Dual Co-polarized SAR measurements of the ocean surface," IEEE Geosci. and Remote Sens. Letters, vol. 10, no. 4, 2013.

[8] R. Ressel, S. Singha, S. Lehner, A. Rösel, and G. Spreen, "Investigation into Different Polarimetric Features for Sea Ice Classification Using X-Band Synthetic Aperture Radar," IEEE JSTARS, vol. 9, no. 7, pp. 3131-3143, July 2016.

[9] B. Minchew, C. Jones, and B. Holt, "Polarimetric Analysis of Backscatter from the Deepwater Horizon oil spill using L-band Syntheic Aperture Radar," IEEE Trans. Geosci. Remote Sens, vol. 50, no. 10, pp. 3812-3830, 2012.

[10] H. Wakabayashi, T. Matsuoka, K. Nakamura, and F. Nishio, "Polarimetric characteristics of sea ice in the Sea of Okhotsk observed by airborne L-band SAR," IEEE Trans. Geosci. Remote Sens, vol. 42, no. 11, pp. 2412-2425, 2004.

[11] C. Jones, K.-F. Dagestad, Ø. Breivik, B. Holt, J. Röhrs, K. Christensen, M. Espeseth, C. Brekke, and S. Skrunes, "Measurement and modeling of oil slick transport," JGR: Oceans, vol. 121, pp. 7759-7775, 2016.

[12] A. Fore, B. Chapman, B. Hawkins, S. Hensley, C. Jones, T. Michel, and R. Muellerschoen, "UAVSAR polarimetric calibration," IEEE Trans. Geosci. Remote Sens, vol. 53, no. 6, pp. 3481-3491, 2015.

[13] A. Doulgeris and T. Eltoft, "Scale mixture of gaussian modelling of polarimetric sar data," EURASIP. J. Appl. Signal Process, 2010.

[14] M. A. Granskog, P. Assmy, S. Gerland, G. Spreen, H. Steen, and L. H. Smedsrud, "Arctic research on thin ice: Consequences of Arctic sea ice loss," EOS, vol. 97, 2016.

[15] W. Dierking, "Mapping of Different Sea Ice Regimes Using Images From Sentinel-1 and ALOS Synthetic Aperture Radar," IEEE Trans. Geosci. Remote Sens, vol. 48, no. 3, pp. 1045-1058, March 2010. 